\title{
Surgical site infection and pathogens in Ethiopia: a systematic review and meta- analysis
}

Yeneabat Birhanu ${ }^{1 *}$ and Aklilu Endalamaw ${ }^{2}$

\begin{abstract}
Background: Surgical site infection is a common complication in patients who underwent surgery. The prevalence is higher in low-income countries. In Ethiopia, prevalence and pathogens of surgical site infection (SSI) reported are variable. This systematic review and meta-analysis aimed to find the pooled prevalence of SSI. Besides, it aimed to find pathogens of surgical site infection in Ethiopia.

Methods: The databases for the search were PubMed, Web of Science, and Google Scholar by the date 21/08/ 2018. To assess publication bias Egger's test regression analysis was applied. Subgroup analysis was conducted based on the study population and region.

Results: This meta-analysis included a total of 15 studies with 8418 study subjects. The pooled prevalence of surgical site infection was $25.22 \%$ (95\% Cl: 17.30 to 33.14\%). Staphylococcus aureus (30.06\%) was the most common pathogen identified. Followed by Escherichia coli (19.73\%), Klebsiella species (17.27\%), and Coagulase-Negative staphylococci (12.43\%) were the commonly isolated pathogens.

Conclusions: The national prevalence of surgical site infection was high. The most common identified pathogen was Staphylococcus aureus. Followed by Escherichia coli, Klebsiella species, and Coagulase-Negative staphylococci. Strict adherence to surgical site infection prevention techniques needs to get more attention.
\end{abstract}

Keywords: Bacteria, Pathogen, Surgical site infection, Ethiopia

\section{Background}

Surgical site infection (SSI) is one of the global health problems [1].. It contributes to occur antibiotic resistance that further leads to life-threatening morbidity [2]. It also increases hospital stay and costs of healthcare services [3, 4]. Besides, it surges the economic burden and impaired quality of life of the patients [5]. Moreover, according to the CDC report, SSI causes 3\% of death by the end of 2015 [1].

Effective infection prevention activities have implemented in national and international settings. These are because of to prevent and control devastating health problems. Notable, improving surgical techniques, operating rooms, and providing antimicrobial prophylaxis [6]. The others include decontamination, preoperative bathing,

\footnotetext{
*Correspondence: birhanuyeneabat@gmail.com

'Department of Surgical Nursing, School of Nursing, College of Medicine and Health Sciences, University of Gondar, Gondar, Ethiopia

Full list of author information is available at the end of the article
}

decolonization with mupirocin ointment, enhancing nutrition [7]. Yet, surgical site infection remains one of the common causes of healthcare-associated infection.

A first global report claimed that SSI is one of the most major problems. This has shown that it occurred in every type of surgical procedure [8]. According to the 2016 WHO report, after the surgery infected patients were 11\% [7]. Its burden reported both in developed and developing countries. In mainland China, SSI reported as $4.5 \%$ [9],14.8\% in sub-Sahara Africa [10], $16.4 \%$ in Uganda [11], and $13.0-22.05 \%$ in Nigeria [12, 13]. Another systematic review study reported the burden of bacterial pathogens. The most common isolated organism for SSI was Staphylococcus aureus (S. aureus (30.4\%) [4]. Coagulase-Negative staphylococci (CONS) (11.7\%), E. coli (9.4\%), E. faecalis (5.9\%), Pseudomonas aeruginosa (5.5\%),Enterobacter species (4.0\%), and Klebsiella species (4.0\%) were also isolated [7].

(C) The Author(s). 2020 Open Access This article is distributed under the terms of the Creative Commons Attribution 4.0 International License (http://creativecommons.org/licenses/by/4.0/), which permits unrestricted use, distribution, and 
In Ethiopia, different studies had conducted to find the prevalence of SSI and pathogens. The prevalence of SSI found in the range between 6.4 to $75.5 \%[14,15]$ in the Ethiopian setting. Hence, discrepancies between studies make difficult to represent the national prevalence. Having national representative data is real to underpin effective prevention and control strategies. Thus, a need to have a pooled estimation of SSI recognizes at the country level. This systematic review and meta-analysis aimed to find the pooled prevalence of SSI. Besides, it aimed to find pathogens of SSI in the Ethiopian setting. The review question was what are the prevalence and pathogens for SSI in Ethiopia?

\section{Methods \\ Reporting}

The Preferred Reporting Items for Systematic Reviews and Meta-analyses (PRISMA) guideline [16] was used to report this meta-analysis (Additional file 1 research checklist).

\section{Literature search}

The databases for the search were Medline (PubMed), Web of Science, and Google Scholar databases. The terms for the search were pre-defined for a comprehensive search strategy. These included all fields within records and Medical Subject Headings (MeSH terms). In the Boolean operator, within each axis, we combined keywords with the "OR" operator. Then we linked the search strategies for the two axes with the "AND" operator. The search terms used for the search were "Surgical site infection" OR "hospital-acquired infection" OR "nosocomial infection" OR "wound site infection" OR "surgical wound site infection" AND "prevalence" OR "distribution" OR "incidence" OR "burden" OR "epidemiology" AND "pathogens" OR "bacteria" AND "Ethiopia". The specific searching detail in PubMed with $\mathrm{MeSH}$ terms was ("prevalence of surgical site infection" [MeSH Terms] OR "surgical site infection" [MeSH Terms] OR "hospital-acquired infection" [MeSH Terms] OR "nosocomial infection" [MeSH Terms] OR "wound site infection" [MeSH Terms] OR "surgical wound site infection" [MeSH Terms] AND "prevalence" [All Fields]) OR "distribution" [MeSH Terms] OR "incidence" [MeSH Terms] OR "burden" [MeSH Terms] OR "epidemiology" [MeSH Terms] AND pathogens of surgical site infection [All Fields]) AND ("Ethiopia" [MeSH Terms] by the date $21 / 08 / 2018$. The publication year of the studies was not limited during the search.

\section{Study selection}

All retrieved studies were exported to Endnote version 7 (Thomson Reuters, London) reference manager. It is the study selection method that we used to remove duplicated studies.

The retrieved articles were screened according to predefined inclusion and exclusion criteria. Discussion and/ or involvement of the third reviewer resolved any disagreements.

\section{Eligibility criteria Inclusion criteria}

Included studies were articles that reported the prevalence of SSI and/or bacterial pathogens. It also included studies published in English and studies conducted only in Ethiopia.

\section{Exclusion criteria}

Excluded criteria were articles without full-text available and qualitative studies. Other excluded criteria were any reviews, commentaries, consultants' corners, letters, and conference abstracts.

\section{Quality assessment}

We used Joanna Brigg's Institute (JBI) quality appraisal criteria [17].. It is the assessment tool used to check the quality of each article. The tool consists of nine major items. The first item is appropriate to the sample frame. The second is the appropriate sampling technique. The third is the adequacy of the sample size. The fourth is a description of the study subjects and settings. The fifth is enough coverage of data analysis. The sixth is the validity of the method for identification of the condition. The seventh item is a standard and reliable measurement for all participants. The eighth is the appropriateness of statistical analysis. And the last item is adequacy and management of response rate. Studies considered low-risk when it would fit 5 or above quality assessment checklists.

\section{Data extraction}

A standardized form was used to extract data by two authors. The following information from each article was extracted. Such as first author, and publication year, the study design, and study population. The location of the study and the type of bacteria were also extracted.

\section{Outcome measurement}

This systematic review and meta-analysis have two major outcomes. The first outcome is to determine the prevalence of SSI in Ethiopia. It calculated as dividing the number of patients who develop SSI to the total number of patients multiply by 100 . A total number of patients refer to patients underwent surgery in the study period. The second outcome of the study was to identify the pathogens of surgical site infection. SSI is an infection where a person presents with signs and symptoms of the infection $[18,19]$. 


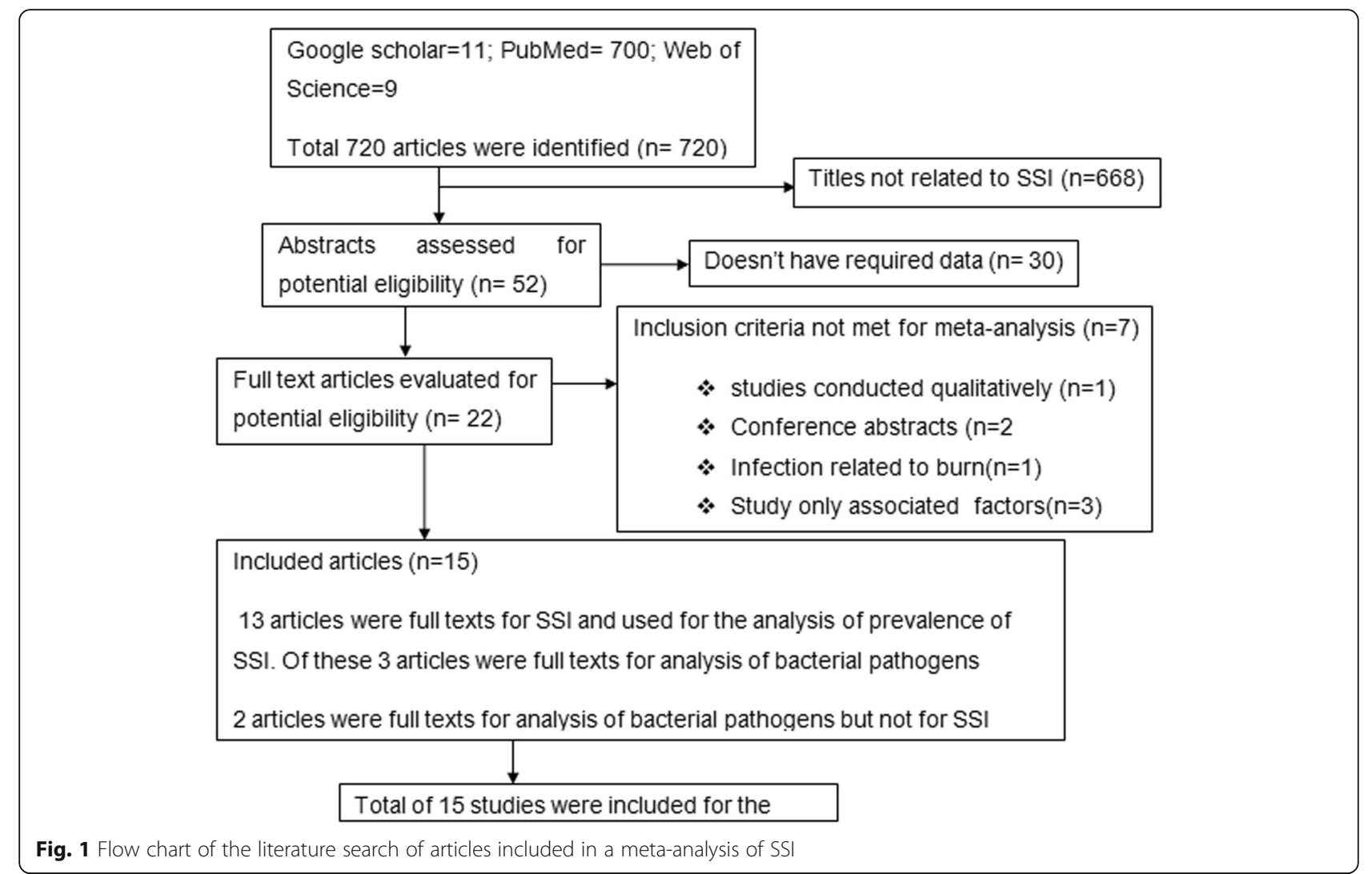

\section{Data analysis}

The required data were collected using a Microsoft Excel 2010 workbook form. Used to collect the required data. Then, the STATA Version11 software was used to analyze the data. The original articles presented using tables and forest plots. A weighted inverse variance random-effects model [20] used to estimate the pooled prevalence. $\mathrm{I}^{2}$ statistics used to assess the percentage of total variation across studies [21]. $\mathrm{I}^{2} \leq 25 \%$ suggested more homogeneity, $25 \%<\mathrm{I}^{2} \leq 75 \%$ suggested moderate heterogeneity, and $\mathrm{I}^{2}>75 \%$ suggested high heterogeneity [21]. Egger's regression test was also used to assess publication bias [22]. Furthermore, the sub-group analysis carried out based on the region of studies. This reduces

Table 1 Characteristics of included studies in the meta-analysis of SSI

\begin{tabular}{|c|c|c|c|c|c|}
\hline Author/Year & Study year & Region & Study design & Sample size & Prevalence \\
\hline Gelaw KA et al./2017 [14] & July 2013-June 2016 & Tigray & Cross-sectional & 384 & 6.4 \\
\hline Asres G et al./2017 [15] & March-August 2015 & Addis Ababa & Cross-sectional & 197 & 75.5 \\
\hline Taye M/2005 [23] & January 1999-December 1999 & Addis Ababa & Cross-sectional & 1754 & 14.8 \\
\hline Melaku S et al./2012 [24] & April-August 2009 & Amhara & Cross-sectional & 961 & 17.1 \\
\hline Mengasha RE et al./2014 [25] & January-June 2012 & Tigray & Cross-sectional & 128 & 75 \\
\hline Gelaw A et al./2014 [26] & November 2010-February 2011 & Amhara & Cross-sectional & 510 & 8.2 \\
\hline Yalew WW et al./2016 [27] & March-April and July 2015 & Amhara & Cross-sectional & 908 & 51.1 \\
\hline Dessie W et.al/2016 [28] & October 2013-March 2014 & Addis Ababa & Cross-sectional & 1088 & 9.8 \\
\hline Wodajo S et al./2017 [29] & June 2012-May 2013 & SNNP & Cross-sectional & 592 & 11 \\
\hline Laloto TL et.al/2017 [30] & March 2-May 2, 2015 & SNNP & Cross-sectional & 105 & 19.1 \\
\hline Mamo T et al./2017 [31] & May-September 2015 & Oromia & Cross-sectional & 384 & 9.4 \\
\hline Ali S et al./2018 [32] & May-September 2016 & Oromia & Cross-sectional & 450 & 22 \\
\hline Dacho AM/2018 [33] & March 10-30, 2017 & SNNP & Cross-sectional & 325 & 12.9 \\
\hline
\end{tabular}




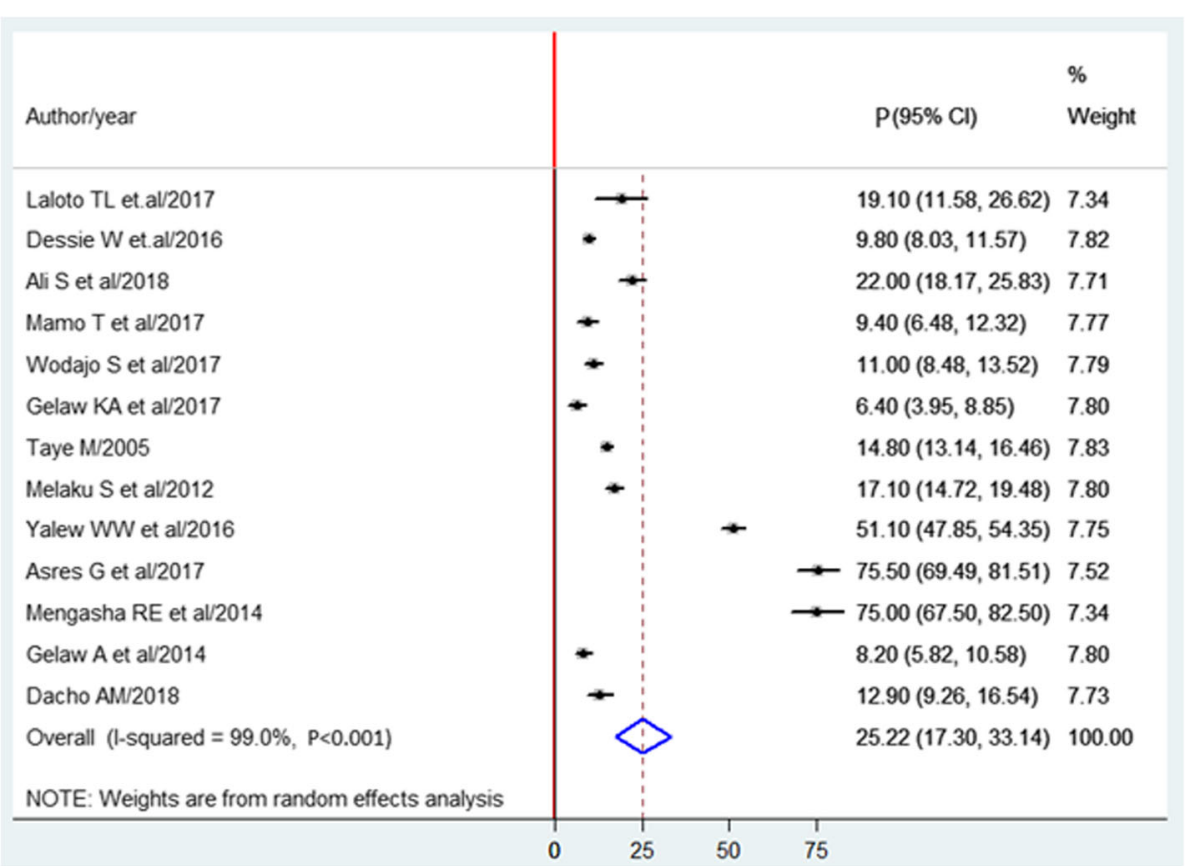

Fig. 2 Forest plot of prevalence with corresponding 95\% Cls of the thirteen studies on SSI. The midpoint and the length of each segment indicated prevalence and a $95 \% \mathrm{Cl}$. The diamond shape showed the combined prevalence of all studies

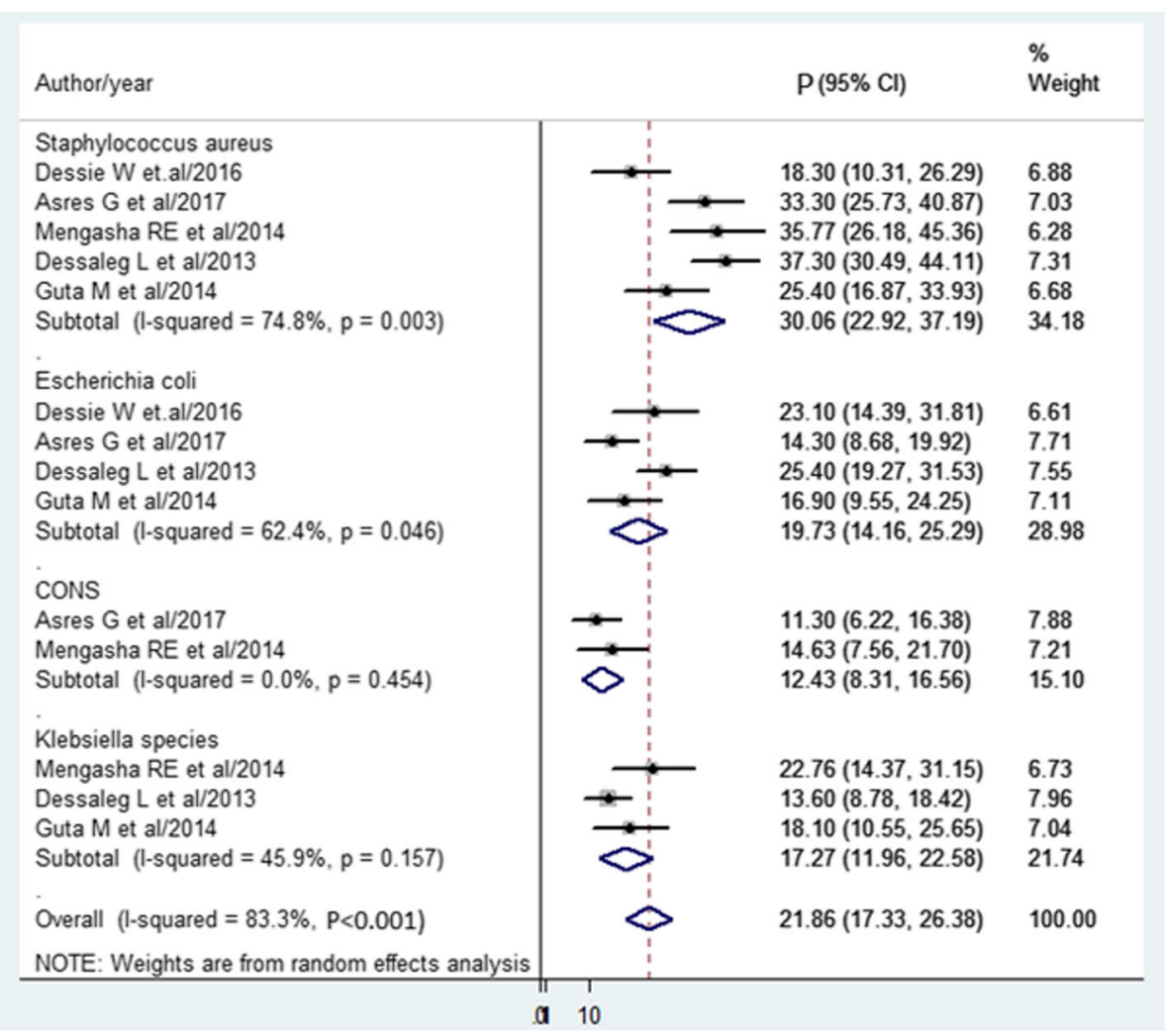

Fig. 3 Forest plot of prevalence with corresponding $95 \% \mathrm{Cls}$ of pathogens. The midpoint and the length of each segment indicated prevalence and a $95 \% \mathrm{Cl}$. The diamond shape showed the combined prevalence of all studies 
the random discrepancies between the point estimates of the primary study.

\section{Results}

\section{Literature search result}

A comprehensive literature search of the database yielded a total of 720 publications. Among these, 705 disregarded due to qualitative study, abstracts, conference abstracts, and titles. Of 15 eligible studies, identified for SSI were 13 studies [14, 15, 23-33] with 7786 study participants. Studies identified for pathogens were Five studies $[15,25,28,34,35]$ with 629 subjects. These five studies conducted on patients who already developed surgical site infections. Finally, this meta-analysis includes a total of 15 studies with 8418 subjects [14, 15, 23-35] (Fig. 1).

\section{Characteristics of included studies}

The range of publication year for included studies was from 2005 to 2018. Four regions and Addis Ababa, the capital city of Ethiopia was the settings studies found. Five in Southern Nation, Nationalities, and People Region (SNNPR) [29, 30, 33-35], three in Addis Ababa [15, 23, 28], three in Amhara [24, 26, 27], two in Oromia [31, $32]$, and two in Tigray region [14, 25]. All included studies were done by using the cross-sectional study design (Table 1).

Five of the studies have reported isolated bacterial pathogens from SSI [15, 25, 28, 34, 35] (Additional file 1).

We did an assessment of studies with JBI quality appraisal checklists. Based on this, none of the included studies was poor quality status.

\section{Meta-analysis}

The absence of publication bias was assessed with Egger's regression test $(p=0.068)$, which showed that no publication bias.

The pooled prevalence of SSI estimated from 13 studies $[14,15,23-33]$ was $25.22 \%(95 \%$ CI, 17.30 to $33.14 \%)$ (Fig. 2). The pooled prevalence of pathogens from five studies $[15,25,28,34,35]$ showed that $S$. aureus $(30.6 \%)$ was most prevalent. Followed by E.coli (19.73\%), Klebsiella spp. (17.27\%), and CONS (12.43\%) (Fig. 3).

\section{Subgroup analysis}

Based on the subgroup analysis, the Tigray region ranked first (40.60\%). Followed by Addis Ababa (32.96\%), Amhara (25.44\%), and Oromia region (15.64\%) were the regions ranked. The report of the lowest prevalence of SSI was from the SNNPR (12.95\%) (Fig. 4).

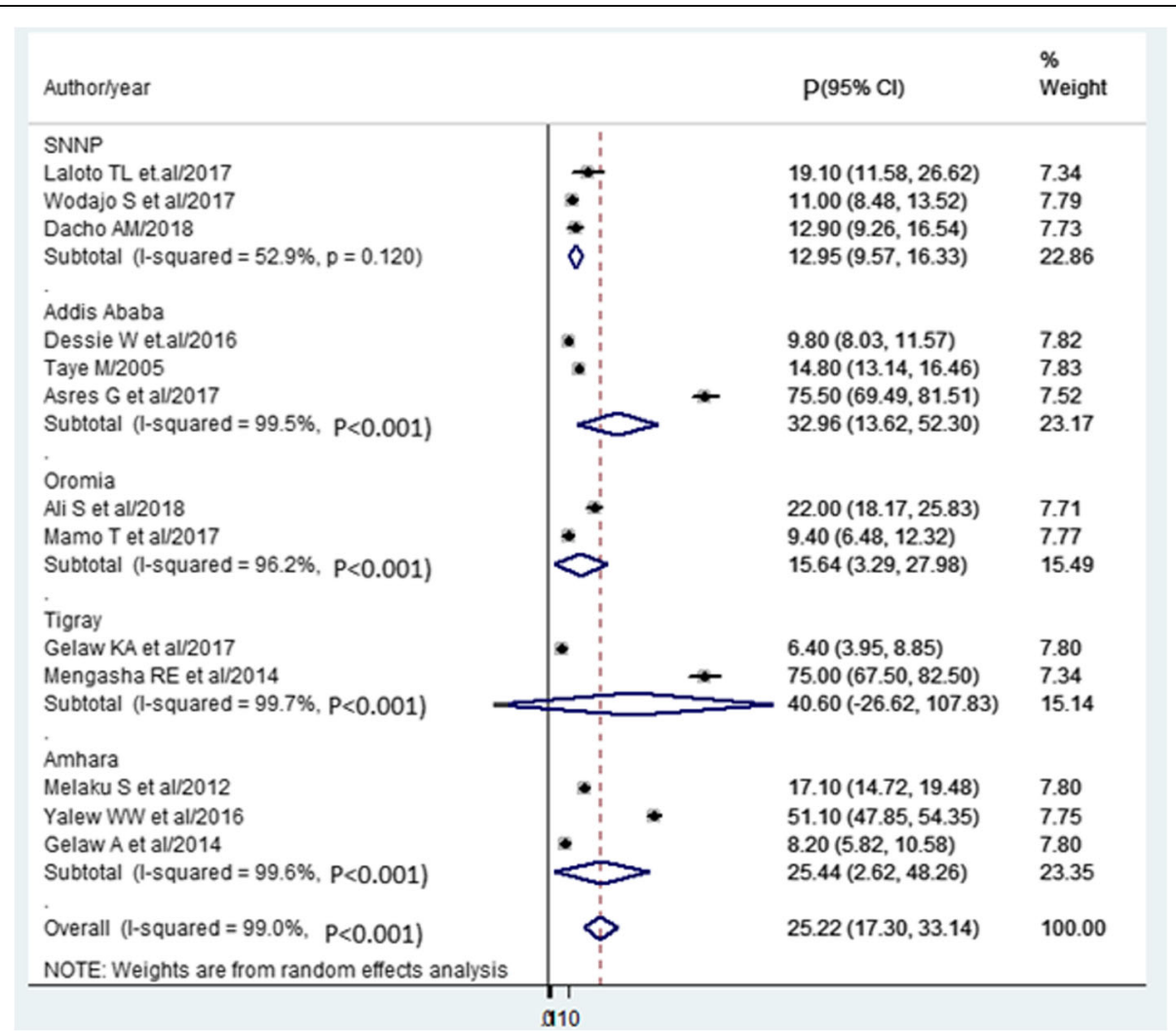

Fig. 4 Forest plot of prevalence with corresponding 95\% Cls on the region. The midpoint and the length of each segment indicated prevalence and a $95 \% \mathrm{Cl}$. The diamond shape showed the combined prevalence of all studies 
The subgroup analysis was also done based on the study population. Eight studies done on all surgical patients showed that the prevalence of SSI was 34.53\%. The pooled prevalence of mothers with Cesarean Section (CS) found to be $10.92 \%$ (Fig. 5).

\section{Discussion}

Surgical site infection continues a global burden of infectious diseases. Particularly, it is common infectious diseases in resource-limited countries including Ethiopia $[14,15]$.

According to this meta-analysis, the estimation of SSI found was $25.22 \%(17.30,33.14)$ in Ethiopia. This is comparable with the study conducted in Tanzania [36] and Nigeria [13]. Factors of surgical site infection are almost similar in developing countries [37]. Besides, infection prevention methods or surgical settings might be similar in developing countries.

This study is higher than a study conducted in Burundi and the Democratic Republic of Congo [38]. This discrepancy might be due to the difference in the study population. In the current study, the prevalence of SSI estimated from all surgical patients. In later, the SSI estimated from only the CS cases.
The current finding is higher than the study from Mainland China [9] and Southeast Asia [39]. This difference might be due to the lack of infection control guidelines. Evidence shows that prophylaxis often administered too early or too late during surgery. This is the condition that, prophylaxis to be ineffective in reducing patient harm [40, 41]. Moreover, negligence [42], improper sterilization [43], poor hand hygiene [44] might increases SSI. But not preoperative bathing, enhanced nutritional support, perioperative discontinuation of immunosuppressive agents [45].

Based on the subgroup analysis, the regional prevalence of SSI was also determined. The highest prevalence of SSI noted in the Tigray region of Ethiopia (40.6\%). This is almost three times higher than a result of Southern Ethiopia (12.95\%). This might be the study conducted in the Tigray region was teaching hospitals. But, the studies done in Southern Ethiopia were district hospitals. This is the site designed to give only healthcare service rather than teaching.

Based on bacterial pathogen estimation, the most common identified pathogen was $S$. aureus. The same report from India [46], Nigeria [12], and Uganda [47] showed that S.aureus found the most common causes of SSI. This might be due to S.aureus is part of human skin

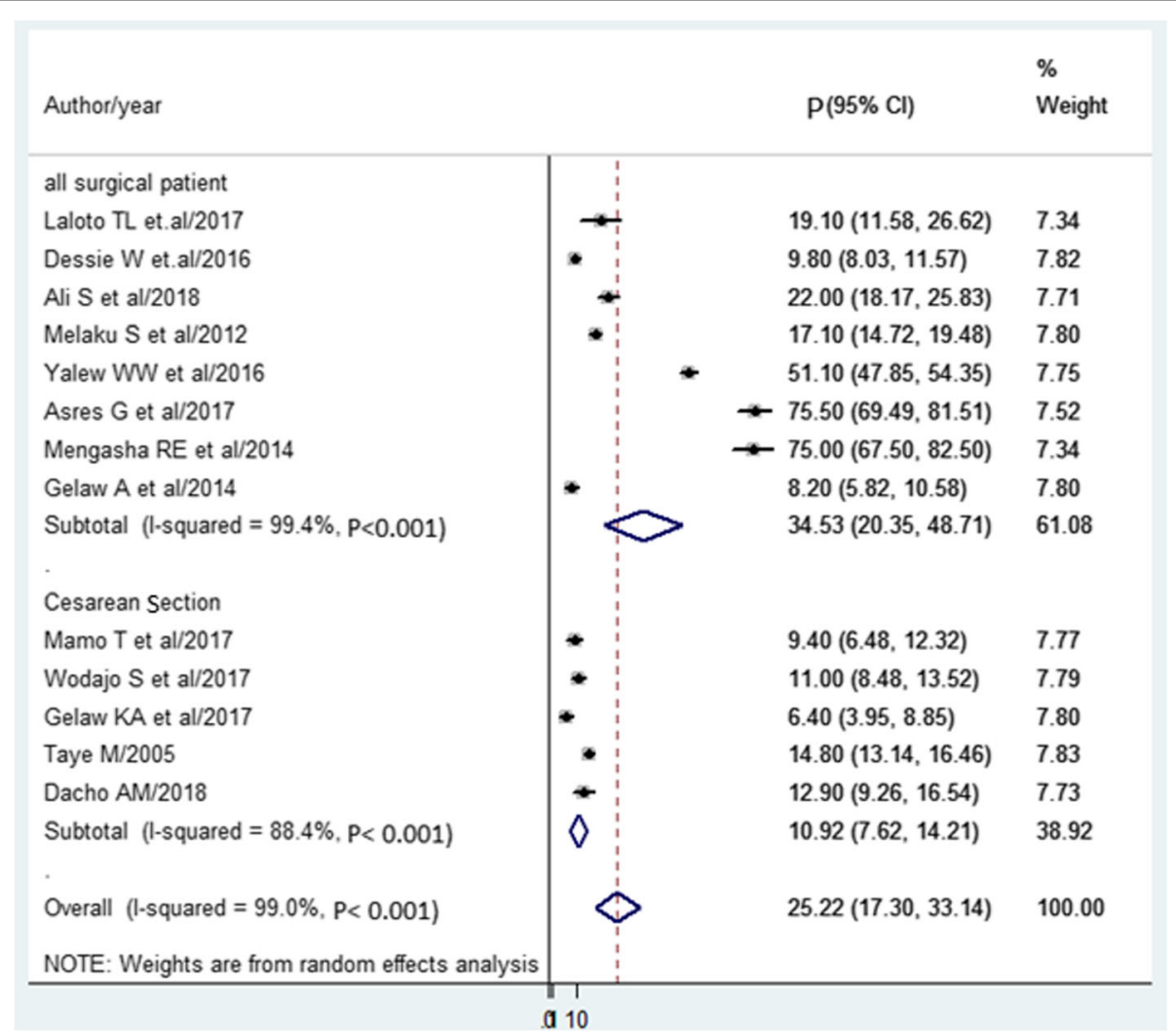

Fig. 5 Forest plot of prevalence with corresponding 95\% Cls on the type of surgery. The midpoint and the length of each segment indicated prevalence and a $95 \% \mathrm{Cl}$. The diamond shape showed the combined prevalence of all studies 
normal flora [48]. So, during the surgical procedure, it could enter into the internal surface of the body. This finding helps healthcare policy and/or decision-makers to consider SSI prevention principles.

Due to the lack of studies in some locations of Ethiopia, the result may not represent a national figure. Although $I^{2}$ is not an absolute measure of heterogeneity, high heterogeneity was observed.

\section{Conclusions}

In this finding, the prevalence of SSI was higher compared to the standard CDC guidelines for SSI [49]. Tigray region ranked first followed by Addis Ababa, Amhara, and Oromia region. While the lowest prevalence observed in the Southern region. The most common identified pathogen of SSI was Staphylococcus aureus. Followed by identified pathogens are Escherichia coli, Klebsiella spp, and CONS. Thus, efforts should make to ensure the prevention of surgical site infection. It means healthcare facilities give more emphasis on infection control measures. Furthermore, effective preand post-operative antibiotics should give to patients undergoing surgery. Finally, active SSI surveillance and infection prevention strategies must be established at the national level.

\section{Supplementary information}

Supplementary information accompanies this paper at https://doi.org/10. 1186/s13037-020-00232-y.

Additional file 1. Research checklist. Characteristics of included studies in the meta-analysis of bacterial pathogens.

\section{Abbreviations}

Cl: Confidence Interval; CONS: Coagulase-Negative staphylococci; SNNPR: Southern Nations and Nationalities of People Region; SPP: Species; SSI: Surgical Site Infection

\section{Acknowledgments}

Not applicable.

\section{Authors' contributions}

YB: Design and planning of the study, review of the literature. More to the point YB contributes data analysis and drafting manuscript. AE: literature review, data collection and took part to realize statistical analysis. Both authors have read and approved the manuscript.

\section{Funding}

There is no fund received from any fund agency.

\section{Availability of data and materials}

No need of more data. All information stated in the manuscript and, its supplementary information files.

\section{Ethics approval and consent to participate}

No need approval from the ethical committee. Because there is no primary data collected.

\section{Consent for publication}

Not applicable.

\section{Competing interests}

The authors declare that they have no competing interests.

\section{Author details}

${ }^{1}$ Department of Surgical Nursing, School of Nursing, College of Medicine and Health Sciences, University of Gondar, Gondar, Ethiopia. ${ }^{2}$ Department of Pediatrics and Child Health Nursing, School of Health Sciences, College of Medicine and Health Sciences, Bahir Dar University, Bahir Dar, Ethiopia.

Received: 17 October 2019 Accepted: 17 February 2020

Published online: 21 February 2020

\section{References}

1. CFD Control, Prevention. Surgical site infection (SSI) event. Atlanta: Centers for Disease Control and Prevention; 2015. p. 1-27.

2. CFD Control, Prevention. Surgical Site Infection (SSI) Event, vol. 2014. Atlanta: CDC; 2014.

3. Tariq A, Ali H, Zafar F, Sial A, Hameed K, Naveed S. A systemic review on surgical site infections. Classification, risk factors, treatment complexities, economical and clinical scenarios. Bioequiv Availab. 2017;9(1):336-40.

4. World Health Organization. Global guidelines for the prevention of surgical site infection. Geneva: World Health Organization; 2016.

5. Badia J, Casey A, Petrosillo N, Hudson P, Mitchell S, Crosby C. Impact of surgical site infection on healthcare costs and patient outcomes. A systematic review in six European countries. J Hosp Infect. 2017;96(1):1-15.

6. WHO. Report on the burden of endemic healthcare-associated infection worldwide. 2011.

7. WHO. Global guidelines for the prevention of surgical site infection: World Health Organization; 2016.

8. Khan HA, Baig FK, Mehboob R. Nosocomial infections: epidemiology, prevention, control, and surveillance. Asian Pac J Trop Biomed. 2017;7(5): 478-82.

9. Fan $Y$, Wei $Z$, Wang $W$, Tan $L$, Jiang $H$, Tian $L$, et al. The incidence and distribution of surgical site infection in mainland China. A meta-analysis of 84 prospective observational studies. Sci Rep. 2014;4:6783.

10. Ngah J, Bénet T, Djibrilla Y. Incidence of surgical site infections in subSaharan Africa: Systematic review and meta-analysis. Afr Field Epidemiol Netw. 2016;24:171

11. Lubega A, Joel B, Justina LN. Incidence and etiology of surgical site infections among emergency postoperative patients in mbarara regional referral hospital, South Western Uganda. Surgery Res Pract. 2017;2017; 6365172.

12. Amoran $\mathrm{O}$, Sogebi A, Fatugase $\mathrm{O}$. Rates and risk factors associated with surgical site infections. Atertiary care center in South-Western Nigeria. INT J Trop Dis Health. 2013;3(1):25-36.

13. Dalhatu A, Olaogun A, Olayinka A, Ahmed S, Timothy G, Yunusa U. Incidence of surgical site infections (SSIs) among patients undergoing major surgery. General hospital Funtua, Katsina state, Nigeria. IOSR J Nurs Health Sci. 2014;3:16-21.

14. Gelaw KA, Aweke AM, Astawesegn FH, Demissie BW, Zeleke LB. Surgical site infection and its associated factors following cesarean section. A crosssectional study from a public hospital in Ethiopia. Patient Safety Surg. 2017; 11(1):18.

15. Asres $\mathrm{G}$, Legese M, Woldearegay G. Prevalence of Multidrug- Resistant Bacteria in Postoperative Wound Infections. Tikur Anbessa Specialized Hospital, Addis Ababa, Ethiopia. Arch Med. 2017;9(4):12.

16. Liberati A, Altman DG, Tetzlaff J, Mulrow C, Gøtzsche PC, loannidis JP, et al. The PRISMA statement for reporting systematic reviews and meta-analyses of studies that evaluate health care interventions. Explanation and elaboration. PLoS Med. 2009;6(7):e1000100.

17. Pearson A, Wiechula R, Court A, Lockwood C. The JBI model of evidencebased healthcare. Int J Evid-Based Healthcare. 2005;3(8):207-15.

18. Horan TC, Andrus M, Dudeck MA. CDC/NHSN surveillance definition of health care-associated infection and criteria. Am J Infect Control. 2008;36(5): 309-32.

19. Horan TC, Emori TG. Definitions of key terms used in the NNIS system. Am J Infect Control. 1997;25(2):112-6.

20. DerSimonian R, Kacker R. Random-effects model for meta-analysis of clinical trials. An update. Contemp Clin Trials. 2007;28(2):105-14.

21. Higgins JP, Thompson SG, Deeks JJ, Altman DG. Measuring inconsistency in meta-analyses. BMJ. 2003;327(7414):557. 
22. Peters JL, Sutton AJ, Jones DR, Abrams KR. RushtonL. Comparison of two methods to detect publication bias in meta-analysis. Jama. 2006;295(6):676-80.

23. Taye M. Wound infection in Tikur Anbessa hospital, surgical department. Ethiop Med J. 2005:43(3):167-74.

24. Melaku S, Gebre-Selassie S, Damtie M, Alamrew K. Hospital- acquired infections among surgical, gynecology and obstetrics patients. Felege-Hiwot referral hospital, Bahir Dar, Northwest Ethiopia. Ethiop Med J. 2012;50(2): 135-44.

25. Mengesha RE, Kasa BG-S, Saravanan M, Berhe DF, Wasihun AG. Aerobic bacteria in post- surgical wound infections and patterns of their antimicrobial susceptibility. Ayder Teaching and Referral Hospital, Mekelle, Ethiopia. BMC Res Notes. 2014;7(1):575.

26. Gelaw A, Gebre-Selassie S, Tiruneh M, Mathios E, Yifru S. Isolation of bacterial pathogens from surgical site infections and possible sources of infections. University of Gondar Hospital, Northwest Ethiopia. Environ Occup Sci. 2014;3(2):103-8.

27. Yallew WW, Kumie A, Yehuala FM. Point prevalence of hospital-acquired infections in two teaching hospitals of Amhara region in Ethiopia. J Drug Healthcare Patient Safety. 2016;8:71.

28. Dessie W, Mulugeta G, Fentaw S, Mihret A, Hassen M, Abebe E. A pattern of bacterial pathogens and their susceptibility isolated from surgical site infections. Selected referral hospitals, Addis Ababa, Ethiopia. Int J Microbiol. 2016;1:2-7.

29. Wodajo S, Belayneh M, Gebremedhin S. Magnitude and factors associated with post-cesarean surgical site infection. Hawassa University teaching and referral hospital, southern Ethiopia. A cross-sectional study. Ethiop J Health Sci. 2017;27(3):283-90.

30. Laloto TL, Gemeda DH, Abdella SH. Incidence and predictors of surgical site infection in Ethiopia: prospective cohort. BMC Infect Dis. 2017;17(1):119.

31. Mamo T, Abebe TW, Chichiabellu TY, Anjulo AA. Risk factors for surgical site infections in obstetrics. A retrospective study in an Ethiopian referral hospital. Patient Safety Surg. 2017;11(1):24.

32. Ali S, Birhane M, Bekele S, Kibru G, Teshager L, Yilma Y, et al. Healthcareassociated infection and its risk factors among patients admitted to a tertiary hospital in Ethiopia: longitudinal study. Antimicrob Resist Infect Control. 2018;7(1):2.

33. Dacho AM, ATA. Magnitude of Post Caesarean Section surgical site infection and its associated factors among mothers who underwent Caesarean Section. Mizan Tepi University Teaching Hospital, South West Ethiopia, 2017. J Nursing and Care. 2018;7:2.

34. Dessalegn L, Shimelis T, Tadesse E, Gebre-Selassie S. Aerobic bacterial isolates from post-surgical wound and their antimicrobial susceptibility pattern. Ahospital- based cross-sectional study. J Med Res. 2014;3(2):18-23.

35. Guta M, Aragaw K, Merid Y. Bacteria from infected surgical wounds and their antimicrobial resistance. Hawassa University referral teaching hospital, Southern Ethiopia. Afr J Microbiol Res. 2014;8(11):1118-24.

36. Mawalla B, Mshana SE, Chalya PL, Imirzalioglu C, Mahalu W. Predictors of surgical site infections among patients undergoing major surgery. Bugando Medical Centre in Northwestern Tanzania. J BMC Surg. 2011;11(1):21.

37. Allegranzi B, Nejad SB, Combescure C, Graafmans W, Attar H, Donaldson $L$, et al. Burden of endemic healthcare-associated infection in developing countries: systematic review and meta-analysis. Lancet. 2011;377(9761):228-41.

38. Chu K, Maine R, Trelles M. Cesarean Section surgical site infections in subSaharan Africa. A multi-country study from Medecins Sans Frontieres. World J Surg. 2015;39:2.

39. Ling ML, Apisarnthanarak A, Madriaga G. The burden of healthcareassociated infections in Southeast Asia. A systematic literature review and meta-analysis. Clin Infect Dis. 2015;60:11.

40. Mahajan RP. The WHO surgical checklist. Best Pract Res Clin Anaesthesiol. 2011:25(2):161-8.

41. Abdulah R. Antibiotic abuse in developing countries. Pharm Regul AFF. 2012;1(2):1000e106.

42. Archibald LK, Reller LB. Clinical microbiology in developing countries. Emerging Infect Dis. 2001;7(2):302.

43. Fast O, Fast C, Fast D, Veltjens S, Salami Z, White MC. Limited sterile processing capabilities for safe surgery in low-income and middle-income countries. Experience in the Republic of Congo, Madagascar and Benin. BMJ Glob Health. 2017;2(Suppl 4):e000428.

44. Asaad AM, Badr SA. Surgical siteinfections in developing countries: .Current burden and futurechallenges. J Clin Microbiol. 2016;5:6.
45. Palumbo VD, Bruno A, Di Trapani B. TomaselloG. WHO global guidelines for the prevention of surgical site infection. A new step to improve patients' safety before, during and after surgery. J Life Safety Secur. 2017;5(5):1-13.

46. Kumar A, Rai A. Prevalence of surgical site infection in general surgery in India. J Int Surg. 2017:4:9.

47. Moses M. Prevalence of surgical site infections in non-diabetic patients undergoing major surgery. St. Francis Hospital Nsambya. Uganda J Med Implants Surg. 2016;1:2.

48. Coates R, Moran J, Horsburgh MJ. Staphylococci: colonizers and pathogens of human skin. Future Microbiol. 2014;9(1):75-91.

49. Anderson DJ, Podgorny K, Berrios-Torres SI, Bratzler DW, Dellinger EP, Greene L, et al. Strategies to prevent surgical site infections in acute care hospitals: 2014 update. Infect Control Hosp Epidemiol. 2014;35(S2):S66-88.

\section{Publisher's Note}

Springer Nature remains neutral with regard to jurisdictional claims in published maps and institutional affiliations.
Ready to submit your research? Choose BMC and benefit from:

- fast, convenient online submission

- thorough peer review by experienced researchers in your field

- rapid publication on acceptance

- support for research data, including large and complex data types

- gold Open Access which fosters wider collaboration and increased citations

- maximum visibility for your research: over $100 \mathrm{M}$ website views per year

At $\mathrm{BMC}$, research is always in progress.

Learn more biomedcentral.com/submissions 